\title{
Association between Nutritional Status and Life Style Practices of Primary School Children in the Colombo District: A Pilot Study
}

\author{
R.M.L.R. Thilakarathne and D.G.N.G. Wijesinghe ${ }^{1^{*}}$ \\ Nutrition Coordination Division, Ministry of Health \\ Public Health Complex, Elwitigala Road \\ Colombo 5, Sri Lanka
}

\begin{abstract}
The objective of this study was to determine the association between nutritional status and life-style practices of primary school children in the Colombo district. A cross-sectional study involving 1347 children was conducted on randomly selected 8 schools in Colombo in 2008. Life style practices were assessed using a questionnaire. Height and weight were measured and height-for-age, weight-for-age and body-mass-index for age were used to define stunting, underweight and obesity respectively. The prevalence of stunting and underweight was $3.8 \%$ and $16.6 \%$, respectively. According to the age specific body-mass-index, $5.1 \%$ were obese, $8.9 \%$ were overweight, and $30.9 \%$ were thin. Overweight and obesity were significantly high among boys while underweight was high among girls. Daily intake of breakfast was seen only in $67.1 \%$. Daily intake of fruits, vegetables and green leaves were $52.1 \%, 71.8 \%$ and $52.9 \%$, respectively. Children who consumed breakfast daily showed significantly high daily intake of vegetables and green leaves. The frequency of consuming fast foods was significantly high among boys studied. According to the leisure activities, $73.3 \%$ were involved predominantly in sedentary type of activities. Television viewing or computing was significantly high among boys. Children who engaged in watching television while consuming food reported poor diet consuming comparatively small quantities of vegetables, green leaves, and fruits daily with a high habitual intake of soft drinks, and fast foods. It can be concluded that the nutrition challenge among primary school children in Colombo is shifting from undernutrition to overweight and obesity, with boys subjected to a higher risk.
\end{abstract}

Key words: Life-style practices, Nutritional status, Obesity, School children, Undernutrition

\section{INTRODUCTION}

The presence of malnutrition in Asia is greater than anywhere else on earth. Seventy percent of the world's malnourished children live in Asia (Gillespie and Haddad, 2001). Overweight and obesity is another spectrum of malnutrition. Childhood obesity has been increasing at an alarming rate throughout the world in the recent past. This emerging problem of overweight in children cannot be ignored. According to the latest estimates from the International Obesity Task Force, at least 155 million school-age children worldwide are overweight or obese (Hossain et al., 2007). Both ends of malnutrition contribute to premature death, impair quality of life and ultimately affect economic development of the country. Unfortunately, Sri Lankan communities consider childhood obesity as a sign of healthiness and high social class

To whom correspondence should be addressed: wijeng@yahoo.com

Department of Food Science and Technology, Faculty of Agriculture, University of Peradeniya Sri Lanka 
because most obese and overweight children are concentrated in urban areas where rapid economic growth is experienced.

Childhood is an important period of rapid physical growth and emotional and cognitive development. It is well known that the wellbeing of this age group is very essential for better health status. According to the Food and Nutrition Policy of Sri Lanka (2004-2010), most national public health programs and policies, as well as national-level research on children have focused on undernutrition. Thus, little is known about both conditions of malnutrition among primary school children who are rapidly undergoing nutritional transition. Colombo district is the commercial capital of Sri Lanka where rapid urbanization occurs and both conditions of malnutrition co-exist. Tackling this double burden of under- and over-nutrition poses a great challenge for which information on proper estimates and causative factors is essential. The present study is an attempt to investigate the contribution of dietary and life style practices of primary school children in relation to their nutritional status.

\section{METHODOLOGY}

\section{Study design, population and sample}

A cross-sectional study involving some National schools was conducted in the Colombo district, the commercial capital of Sri Lanka in 2008. From the 32 AB categorized National schools in the district, mixed schools and schools without a primary section were excluded. Four pairs of schools were randomly selected from the list of socio-demographically- and scholastically-matched boys' and girls' schools. Selected schools were; Royal college, Nalanda College, Mahanama College, Thurstan College, Vishaka Vidyalaya, Sirimavo Bandaranayake Balika Maha Vidyalaya, Kolonnawa Balika Vidyalaya and St. Paul's Balika Vidyalaya. All grades 4 and 5 students aged $9-10$ years in the academic year 2008 were eligible to participate in the study. Among them, a total of 1347 children (665 boys, 682 girls) were selected by randomly selecting 2 clusters from each grade.

\section{Assessment of nutritional status}

Weight, height and waist circumference of all children were measured in the classroom according to the standard procedures (WHO, 1995) using the standard equipment, by welltrained enumerators. NCHS/CDC (2000) references were used to define nutritional indices. Height-for-age and weight-for-age were used to define stunting and underweight $(<-2$ standard deviation from the median value of the references), respectively (WHO, 1995). Body mass index (BMI) is defined as the weight in kilograms divided by the square of the height in meters $\left(\mathrm{kg} / \mathrm{m}^{2}\right)$. Sex specific BMI-for-age references (NCHS/CDC, 2000) were used to define thinness as $<5^{\text {th }}$ percentile, overweight as $\geq 85^{\text {th }}$ to $<95^{\text {th }}$ percentile and obesity as $\geq 95^{\text {th }}$ percentile.

\section{Assessment of life style}

Life style practices were assessed using an interviewer-assisted, self-administered, short questionnaire. This was a pre-structured, pre-tested multiple-choice questionnaire designed to measure qualitative data on life style patterns such as food habits, breakfast intake, physical activities and leisure time activities. 


\section{Data analysis}

Nutritional indices such as height-for-age and weight-for-age $\mathrm{z}$ scores were obtained using EpiInfo 3.5.1 version (CDC, USA). Detailed analysis of data was conducted using SPSS for Windows version 10.0 (SPSS Inc). Descriptive data were summarized as means with standard deviations or percentages and group differences in categorical variables were tested using Pearson's Chi-square test and odds ratios. In Chi-square tests, $p$ values of $<0.05$ and in odds ratios $95 \%$ CI were considered significant.

\section{Ethical clearance}

Permission to conduct the study was obtained from the school authorities. Ethical clearance was obtained from the Ethical Review Committee of the Faculty of Medicine, University of Colombo. The informed written consent was obtained from the parents or guardians after an awareness programme for parents was conducted.

\section{RESULTS AND DISCUSSION}

Among the selected 1347 children, 1155 (85.2\%) had complete data for anthropometric assessment. The descriptive data of the sample are shown in Table 1.

Table 1. Descriptive data on anthropometry by gender and grade

\begin{tabular}{|c|c|c|c|c|c|c|c|}
\hline \multirow{3}{*}{ Characteristics } & \multicolumn{7}{|c|}{ Mean (SD) } \\
\hline & \multirow[t]{2}{*}{ Total } & \multicolumn{3}{|c|}{ Gender } & \multicolumn{3}{|c|}{ Grade } \\
\hline & & Boys & Girls & $p$ & 4 & 5 & $p$ \\
\hline No. of children & 1155 & 564 & 591 & - & 592 & 563 & - \\
\hline Weight (kg) & $\begin{array}{l}27.9 \\
(7.0)\end{array}$ & $\begin{array}{l}28.2 \\
(7.1)\end{array}$ & $\begin{array}{l}27.4 \\
(6.9)\end{array}$ & 0.062 & $\begin{array}{l}26.1 \\
(6.1)\end{array}$ & $\begin{array}{l}29.5 \\
(7.5)\end{array}$ & 0.000 \\
\hline Height (cm) & $\begin{array}{c}132.4 \\
(6.7)\end{array}$ & $\begin{array}{c}132.6 \\
(6.5)\end{array}$ & $\begin{array}{c}132.2 \\
(6.9)\end{array}$ & 0.327 & $\begin{array}{c}129.6 \\
(5.9)\end{array}$ & $\begin{array}{c}135.2 \\
(6.3)\end{array}$ & 0.000 \\
\hline $\begin{array}{l}\text { Waist Circumference } \\
(\mathrm{cm})\end{array}$ & $\begin{array}{l}57.5 \\
(8.0)\end{array}$ & $\begin{array}{l}57.7 \\
(8.4)\end{array}$ & $\begin{array}{l}57.3 \\
(7.7)\end{array}$ & 0.370 & $\begin{array}{l}56.2 \\
(7.5)\end{array}$ & $\begin{array}{l}58.8 \\
(8.4)\end{array}$ & 0.000 \\
\hline BMI $\left(\mathrm{kg} / \mathrm{m}^{2}\right)$ & $\begin{array}{l}15.7 \\
(2.9) \\
\end{array}$ & $\begin{array}{l}15.9 \\
(2.9) \\
\end{array}$ & $\begin{array}{l}15.5 \\
(2.9) \\
\end{array}$ & 0.033 & $\begin{array}{l}15.4 \\
(2.7) \\
\end{array}$ & $\begin{array}{l}16.0 \\
(3.1) \\
\end{array}$ & 0.000 \\
\hline
\end{tabular}

SD- standard deviation, $p$ - probability value of Pearson's Chi-square test

The mean age of the school children was $9.3 \pm 0.6$ years. Gender comparison showed that there were no statistically significant differences in weight, height, and waist circumference between boys and girls (Table 1). However, BMI was significantly higher in boys $(p<0.05)$.

\section{Nutritional status}

A comparison of prevalence of undernutrition in school children by gender and grade is highlighted in Table 2. 
Table 2. Prevalence of undernutrition by gender and grade

\begin{tabular}{lccccccc}
\hline \multirow{2}{*}{ Characteristics } & Total & \multicolumn{3}{c}{ Gender (\%) } & \multicolumn{3}{c}{ Grade (\%) } \\
\cline { 3 - 8 } & $\mathbf{( \% )}$ & Boys & Girls & $\boldsymbol{p}$ & $\mathbf{4}$ & $\mathbf{5}$ & $\boldsymbol{p}$ \\
\hline Stunting & 3.8 & 3.0 & 4.6 & 0.168 & 4.7 & 2.8 & 0.094 \\
Underweight & 16.6 & 13.1 & 20.0 & 0.002 & 17.6 & 15.6 & 0.377 \\
Stunting and/or Underweight & 17.4 & 13.5 & 21.2 & 0.001 & 18.2 & 16.5 & 0.448 \\
\hline
\end{tabular}

The prevalence of stunting and underweight in the total sample was $3.8 \%$ and $16.6 \%$ respectively. Percentage of children showing stunting and/or underweight was 17.4. All these parameters of undernutrition were high in girls than in boys. According to the odds ratios, girls were having 1.65 times (95\% CI 1.203-2.268) higher chance of developing underweight and 1.73 times (95\% CI 1.203-2.268) higher chance of developing stunting and/or underweight condition compared to boys, suggesting that undernutrition condition was highly concentrated in girls. Table 3 gives the gender and grade -wise distribution of the nutritional problems of children based on their BMI-for-age.

Table 3. Prevalence of overnutrition and undernutrition condition of school children according to their gender and grade

\begin{tabular}{lccccccc}
\hline \multirow{2}{*}{ BMI category } & $\begin{array}{c}\text { Total } \\
(\%)\end{array}$ & \multicolumn{3}{c}{ Gender (\%) } & \multicolumn{3}{c}{ Grade (\%) } \\
\cline { 3 - 8 } & 5.1 & 6.9 & 3.4 & 0.006 & 4.9 & 5.3 & 0.740 \\
\hline $\begin{array}{l}\text { Obese } \\
(\text { BMI } \geq 95)\end{array}$ & 8.9 & 10.1 & 7.8 & 0.116 & 8.8 & 9.1 & 0.870 \\
$\begin{array}{l}\text { Overweight } \\
(\text { BMI } \geq 85 \text { \& BMI }<95)\end{array}$ & 14.0 & 17.0 & 11.2 & 0.004 & 13.7 & 14.4 & 0.730 \\
$\begin{array}{l}\text { Overweight or obese } \\
(\text { BMI } \geq 85)\end{array}$ & 30.9 & 28.7 & 33.0 & 0.116 & 30.6 & 31.3 & 0.801 \\
$\begin{array}{l}\text { Thin } \\
(\text { BMI }<5)\end{array}$ & 44.9 & 45.7 & 44.2 & 0.589 & 44.3 & 45.6 & 0.635 \\
$\begin{array}{l}\text { Undesirable BMI } \\
(5>\text { BMI } \geq 85)\end{array}$ & & & & & & & \\
\hline
\end{tabular}

As could be seen in Table 3, in the study sample $5.1 \%$ were obese, $8.9 \%$ were overweight and $30.9 \%$ were thin. The results revealed that $14 \%$ of the children were having undesirably high BMI, 30.9\% having undesirably low BMI and only 55.1\% were within the normal BMI range. Grade 5 students were more vulnerable to become overweight, obese and thin compared to grade 4 students. Boys had a higher prevalence for overweight or obesity $(\mathrm{BMI} \geq 85)$ while girls had a higher prevalence for thinness $(\mathrm{BMI}<5)$. It should be noted that undernutrition problem is still the main prevailing nutrition problem among primary school children in the Colombo district.

Data shows that there was a significant difference $(p<0.01)$ in the prevalence of overweight or obese $(\mathrm{BMI} \geq 85)$ and obese (BMI $\geq 95)$ groups, by gender. According to the odds ratio, boys were 2.12 folds more likely to be obese compared to the girls $(6.9 \%$ vs. $3.4 \%)\left(\mathrm{Chi}^{2}\right.$ value $=7.422, p=0.006, \mathrm{OR}=2.121,95 \%$ CI 1.221-3.683). However, the prevalence of thinness was apparently higher in girls but the difference was not statistically significant. When considering the prevalence of undesirable BMI $(5>\mathrm{BMI} \geq 85)$, the gender difference was not significant. Also, there was no significant difference between the two grades in any BMI category. 
The prevalence of central obesity (abdominal obesity) by gender and grade is given in Table 4. There was no significant difference in the prevalence of central obesity by gender and grade though it was apparently higher in boys and the older group.

Table 4. Waist circumference distribution by gender and grade

\begin{tabular}{lccccc}
\hline \multirow{2}{*}{ Category } & \multirow{2}{*}{ Total $(\%)$} & \multicolumn{2}{c}{ Gender (\%) } & \multicolumn{2}{c}{ Grade (\%) } \\
\cline { 3 - 6 } & & Boys & Girls & $\mathbf{4}$ & $\mathbf{5}$ \\
\hline Normal $\left(<90^{\text {th }}\right.$ percentile $)$ & 96.9 & 96.6 & 97.1 & 97.5 & 96.3 \\
Central obesity $\left(\geq 90^{\text {th }}\right.$ percentile $)$ & 3.1 & 3.4 & 2.9 & 2.5 & 3.7 \\
\hline
\end{tabular}

\section{Life style practices}

Questionnaire on life style practices was only given to the children in grade 5 in the academic year 2009. Of the 686 children in the sample, only $429(62.5 \%)$ completed the questionnaire.

Table 5 presents the daily consumption patterns of different foods among school children. Of them, $98.6 \%$ reported daily consumption of rice while $6.5 \%$ reported daily consumption of bread. Girls reported a high frequency of daily consumption of rice but the gender difference was not statistically significant. Daily intake of fruits and green leaves was poor among primary school children, as only just above half of the children consumed them at least once a day. Results suggest a tendency for girls to eat more fruits and vegetables while boys eating more green leaves, though those differences were not statistically significant $(p>0.05)$. However, the frequency of consuming fruits 3 or more days per week, was significantly high in girls $\left(\mathrm{Chi}^{2}\right.$ value $\left.=7.591, p=0.006, \mathrm{OR}=2.022,95 \% \mathrm{CI} 1.218-3.356\right)$.

Table 5. Daily consumption of different foods

\begin{tabular}{|c|c|c|c|c|c|}
\hline \multirow[b]{2}{*}{ Food item } & \multicolumn{3}{|c|}{ Daily consumption } & \multirow{2}{*}{$\begin{array}{l}\text { Chi- } \\
\text { square }\end{array}$} & \multirow[b]{2}{*}{$p$} \\
\hline & $\begin{array}{l}\text { Total } \\
\text { n (\%) }\end{array}$ & $\begin{array}{l}\text { Boys } \\
\text { n (\%) }\end{array}$ & $\begin{array}{c}\text { Girls } \\
\text { n (\%) }\end{array}$ & & \\
\hline Rice & $423(98.6)$ & $203(98.1)$ & $220(99.1)$ & NA & $0.435^{*}$ \\
\hline Vegetables & $308(71.8)$ & $144(69.6)$ & $164(73.9)$ & 0.982 & 0.322 \\
\hline Fruits & $223(52.1)$ & $105(51.0)$ & $118(53.2)$ & 0.204 & 0.652 \\
\hline Green leaves & 227 (52.9) & $114(55.1)$ & $113(50.9)$ & 0.748 & 0.387 \\
\hline
\end{tabular}

NA - not applicable; * Fisher's exact test

Banana and apple were the most frequently consumed fruits $(47.8 \%$ and $16.2 \%$ respectively) by the children. When considering the pattern of breakfast intake, only $67.1 \%$ reported that they consume breakfast daily while $32.9 \%$ do not. The majority $(68.5 \%)$ consumed their breakfast at home. While $83.6 \%$ of children had their breakfast before going to school, $14.7 \%$ had late breakfast during the interval and $1.6 \%$ skipped the breakfast.

Another interesting observation was that the children who consumed breakfast daily showed significantly higher intake of vegetables and green leaves (Table 6). 
Table 6. Association between breakfast intake and daily intake of vegetables, fruits and green leaves

\begin{tabular}{|c|c|c|c|c|}
\hline \multirow{2}{*}{ Variable } & \multicolumn{2}{|c|}{ Daily breakfast intake n (\%) } & \multirow{2}{*}{$\begin{array}{c}\text { Chi- } \\
\text { square }\end{array}$} & \multirow{2}{*}{$p$} \\
\hline & Yes & No & & \\
\hline Vegetables & $220(76.7)$ & $88(62.4)$ & 9.507 & 0.002 \\
\hline Fruits & $158(55.1)$ & $65(46.4)$ & 2.805 & 0.094 \\
\hline Green leaves & $165(57.5)$ & $62(44.0)$ & 6.938 & 0.008 \\
\hline
\end{tabular}

Table 7 shows the food habits of children based on the frequency of consumption of some selected food items. Consumption of those food items, at least one day per week, was considered as habitual intake. Accordingly, the habitual intake of fast foods and milk was higher $(p<0.05)$ among boys compared to girls. Even though the habitual intake of soft drinks was not significantly different by gender, the frequency of consuming soft drinks 3 or more days per week was significantly lower for girls than boys $\left(\mathrm{Chi}^{2}\right.$ value $=6.740, p=0.009$, $\mathrm{OR}=0.518,95 \%$ CI $0.313-0.855$ ). It was also observed that $77 \%$ of the children had snacks consisted of three main meals which included biscuits $(85.6 \%)$, bite $(5.2 \%)$ and tipitip $(2.6 \%)$.

Table 7. Habitual intake of some selected foods by school children according to the gender

\begin{tabular}{lccccc}
\hline \multirow{2}{*}{ Food item } & \multicolumn{3}{c}{ Eat as a habit n (\%) } & \multirow{2}{*}{ Chi- } & \multirow{2}{*}{$\boldsymbol{p}$} \\
\cline { 2 - 4 } & Total & Boys & Girls & square & \multicolumn{1}{c}{} \\
\hline Soft drinks & $262(61.1)$ & $128(61.8)$ & $134(60.4)$ & 0.098 & 0.754 \\
Fast foods (pastry, roles, pizza) & $308(72.0)$ & $161(78.2)$ & $147(66.2)$ & 7.549 & 0.006 \\
Milk & $385(90.0)$ & $192(93.2)$ & $193(86.9)$ & 4.644 & 0.031 \\
Bread & $379(88.3)$ & $179(86.5)$ & $200(90.1)$ & 1.361 & 0.243 \\
\hline
\end{tabular}

When considering the life style practices, $46.4 \%$ of school children had a habit of eating while watching the TV and there was a significant gender difference (38.3\% girls and $55.1 \%$ boys) in this habit. When playing habits and leisure time activities were questioned, only a few children (6.6\%) reported that they were unable to play and stay active during their dayto-day life. For them, the major reasons for inactive life style were, studies (34.6\%), dislike to play $(26.9 \%)$ and laziness $(19.2 \%)$. When considering the activities during the interval, $80.1 \%$ reported that they play. A majority of school children $(51.2 \%)$ was engaged in reading as a leisure time activity (Table 8).

Table 8. Playing habit and leisure time activities of school children by gender

\begin{tabular}{lccccc}
\hline Habit & $\begin{array}{c}\text { Total } \\
\mathbf{n}(\%)\end{array}$ & $\begin{array}{c}\text { Boys } \\
\mathbf{n}(\mathbf{\%})\end{array}$ & $\begin{array}{c}\text { Girls } \\
\mathbf{N}(\%)\end{array}$ & $\begin{array}{c}\text { Chi- } \\
\text { square }\end{array}$ & $\boldsymbol{p}$ \\
\hline Play as habit & $399(93.4)$ & $194(94.2)$ & $205(92.8)$ & 0.348 & 0.555 \\
Reading in leisure time & $219(51.2)$ & $86(41.7)$ & $133(59.9)$ & 14.106 & 0.000 \\
Active in leisure time & $102(23.8)$ & $58(28.2)$ & $44(19.8)$ & 4.090 & 0.043 \\
TV/computer in leisure time & $88(20.6)$ & $52(25.2)$ & $36(16.2)$ & 5.330 & 0.021 \\
\hline
\end{tabular}

Leisure time activities were grouped into two, as active and inactive. Inactive group $(76.2 \%)$ included reading $(51.2 \%)$, TV viewing $(11.9 \%)$, being at computer $(8.6 \%)$, sleeping $(1.6 \%)$ and others (2.8\% - consist of helping household work, studying, painting, playing chess etc.). The active group, which included only playing, was $23.8 \%$. Boys were more active in leisure 
time than girls $(p<0.05)$. Moreover, proportion of children who spend their leisure time in front of TV or computer was also significantly higher among boys $(25.2 \%)$ than girls $(16.2 \%)(p<0.05)$.

Table 9. Association between food intake pattern and eating habit while watching TV

\begin{tabular}{|c|c|c|c|c|}
\hline \multirow[b]{2}{*}{ Food intake pattern } & \multicolumn{2}{|c|}{ Eating habit n (\%) } & \multirow{2}{*}{$\begin{array}{l}\text { Chi- } \\
\text { square }\end{array}$} & \multirow[b]{2}{*}{$p$} \\
\hline & $\begin{array}{c}\text { Eat while } \\
\text { watching } T V\end{array}$ & $\begin{array}{c}\text { Don't eat while } \\
\text { watching } T V\end{array}$ & & \\
\hline Daily intake of vegetables & $132(66.7)$ & $175(76.4)$ & 4.999 & 0.025 \\
\hline Daily intake of fruits & $98(49.7)$ & $124(54.1)$ & 0.822 & 0.364 \\
\hline Daily intake of green leaves & $99(50.0)$ & $127(55.5)$ & 1.270 & 0.260 \\
\hline Habitual intake of soft drinks & $133(67.2)$ & $128(55.9)$ & 5.682 & 0.017 \\
\hline Habitual intake of fast foods & $159(80.3)$ & $148(64.6)$ & 12.912 & 0.000 \\
\hline
\end{tabular}

The findings indicate that $55.1 \%$ of boys and $38.3 \%$ of girls ate while watching television $(p<0.05)$. Table 9 shows the food intake pattern of children based on their eating habits while watching TV. According to the results, children who were eating while watching TV showed less percentages for daily intake of vegetables $(p<0.05)$, green leaves $(p>0.05)$ and fruits $(p>0.05)$ compared to the children who did not eat while watching TV. At the same time, children who were eating while watching TV showed higher percentages for habitual intake of soft drinks $(p<0.05)$ and fast foods $(p<0.05)$. Therefore, children who ate while watching television consumed soft drinks and fast foods more frequently and vegetables less frequently, when compared to the children who did not eat during TV-viewing.

\section{Association between nutritional status and life style practices}

According to the results shown in Table 10, a clear relationship could not be established between dietary/ life style practices and overweight or obesity condition of primary school children $(p>0.05)$. Similarly, none of these variables showed any relationship with other nutritional indices such as stunting, underweight or obesity.

Table 10. Association of overweight/obese and life style practices of primary school children

\begin{tabular}{|c|c|c|c|c|c|}
\hline Variable & $\begin{array}{l}\text { Total } \\
\text { n }(\%) \\
\end{array}$ & $\begin{array}{c}\mathrm{BMI} \geq 85 \\
\text { n }(\%)\end{array}$ & $\begin{array}{c}\text { BMI }<85 \\
\text { n }(\%) \\
\end{array}$ & $\begin{array}{c}\text { Chi- } \\
\text { square }\end{array}$ & $p$ \\
\hline Daily intake of breakfast & $258(67.5)$ & $35(72.9)$ & $223(66.8)$ & 0.724 & 0.395 \\
\hline Daily intake of vegetables & $276(72.1)$ & $31(64.6)$ & $245(73.1)$ & 1.525 & 0.217 \\
\hline Daily intake of fruits & $196(51.3)$ & $26(54.2)$ & $170(50.9)$ & 0.179 & 0.672 \\
\hline Daily intake of green leaves & $204(53.3)$ & $30(62.5)$ & $174(51.9)$ & 1.881 & 0.170 \\
\hline Habitual intake of milk & $346(90.6)$ & $46(95.8)$ & $300(89.8)$ & NA & $0.140 *$ \\
\hline $\begin{array}{l}\text { Habitual intake of soft } \\
\text { drinks }\end{array}$ & $232(60.6)$ & $25(52.1)$ & $207(61.8)$ & 1.657 & 0.198 \\
\hline $\begin{array}{l}\text { Habitual intake of fast } \\
\text { foods }\end{array}$ & $278(72.8)$ & 35 (72.9) & $243(72.8)$ & 0.001 & 0.981 \\
\hline Intake of snacks & $292(76.6)$ & $37(78.7)$ & $255(76.3)$ & 0.130 & 0.718 \\
\hline $\begin{array}{l}\text { Watch TV/computer in } \\
\text { leisure time }\end{array}$ & $76(19.9)$ & $12(25.0)$ & $36(19.2)$ & 0.898 & 0.343 \\
\hline Read in leisure time & $194(50.8)$ & $25(52.1)$ & $169(50.6)$ & 0.037 & 0.847 \\
\hline Play as habit & $358(94.0)$ & $45(93.8)$ & $313(94.0)$ & 0.004 & 0.947 \\
\hline
\end{tabular}

NA - not applicable, * Fisher's exact test 
This study indicates that the present acute undernutrition (underweight $16.6 \%$ ) was higher compared to chronic undernutrition (stunting 3.8\%) among the primary school children of the selected National schools in the Colombo district. The prevalence of undernutrition reported here was much lower than the findings of anaemia study conducted in 2001 (underweight $30.4 \%$, stunting $19.6 \%$; MRI, 2001) probably because there was a time gap of 9 years and also the present study covered only a sample of National schools in the Colombo district. Due to the limited data analysis on nutritional indices in the anaemia study, genderwise comparison of undernutrition status was not known. The percent study indicated that girls had a significantly higher prevalence for undernutrtion. The prevalence of thinness $(30.9 \%)$, overweight $(8.9 \%)$ and obesity $(5.1 \%)$ observed in the current study are consistent with some existing studies done in the Colombo district (Wickramasinghe et al., 2004 \& Munasinghe et al., 2008) though age ranges are slightly different. Thinness $(B M I<5)$ still prevails as the main nutritional problem among the primary school children in the Colombo district.

When the findings of the present study are compared with similar studies (Wickramasinghe et al., 2004 and Munasinghe et al., 2008) reported previously, a growing trend of overweight and obesity in children is apparent, as in other developed and developing countries of the world. Many studies noted that there is a sex-wise variation in the prevalence of overweight and obesity. In the present study, overweight or obesity and obese groups were significantly higher among boys. Among school children in Taiwan (Chu and Pan, 2007), Korea (Lee et al., 2007), United States (Field et al., 2003) and Chile (Olivares et al., 2004) boys were found to be more obese and overweight. On the contrary, studies done by Wardle et al. (2006) in Britain found that more girls were overweight and obese than boys. All these studies indicate that the sex of the child has an influence on the prevalence of overweight and obesity. However, it was reported by Mian et al. (2002) that no association exists between nutritional status and gender among school children in Pakistan.

According to the overall nutritional status of primary school children, $44.9 \%$ have undesirable BMI, suggesting a widespread adverse nutritional experience among the primary school children in the commercial capital of Sri Lanka. Mian et al. (2002) reported that the cognitive and behavioural developments of the malnourished children are likely to be impaired, leading to educational failure and poor working capacity in adulthood.

The dietary practices of children observed in the present study were not significantly according to the Sri Lankan standards, especially the daily intake of fruits, vegetables and green leaves was not satisfactory. Fruits and vegetable intake and activity pattern of the present study were comparable with some previous studies (Olivares et al., 2004 \& Sluijs et al., 2008). There are some interesting points such as that boys seem to consume fast foods and soft drinks more frequently when compared to girls. In addition, children who ate while watching television had lower-quality diets. These children consumed soft drinks and fast foods more frequently and fruits, vegetables and green leaves less frequently when compared to children who did not eat during television-viewing. These findings concur with previous studies (Coon et al., 2001; Boynton-Jarrett et al., 2003; Field et al., 2003; Halford et al., 2004 \& Dubois et al., 2008). In the present study, higher percentage of boys eat while watching TV. Coon et al. (2001) and Dubois et al. (2008) also reported similar gender differences in television-viewing and eating behaviours. The adverse dietary and lifestyle practices of the boys may have been the reasons for their increased prevalence of obesity.

However, in the present study a direct association between dietary/life style practices and nutritional status of the children could not be established. This could be due to the small 
sample size and the qualitative nature of questionnaire used for life style assessment. Some limitations may influence the interpretation of these results. The short questionnaire used to assess the qualitative data on life style practices would have restricted finding strong associations between body weight and those variables. Therefore, further in-depth studies with quantitative data on lifestyle practices of school children are needed to evaluate the association between nutritional status and dietary/life style practices.

Since participants were recruited from the National schools, children of low socioeconomic status and children in international schools were not covered. Therefore, replication should be done using different samples to increase generalizability. Since this study was crosssectional, a causal association of dietary habits and life style practices with underweight, overweight and obesity should not be inferred. In spite of these limitations this study provided important data on nutritional status and dietary/life style practices of primary school children in urban areas that will help shape the direction of the child nutrition programmes in the future.

\section{CONCLUSION}

Undernutrition remains the main nutritional problem among primary school children of National schools in the Colombo district, while overweight and obesity are emerging at an alarming rate, with boys particularly at risk.

\section{ACKNOWLEDGEMENTS}

School authorities and all subjects who participated in the study are gratefully acknowledged for their cooperation. This study was supported by the World Bank grants under HSDP.

\section{REFERENCES}

Boynton-Jarrett, R., Thomas, T.N., Peterson, K.E., Wiecha, J., Sobol, A.M. and Gortmaker, S.L. (2003). Impact of television viewing patterns on fruit and vegetable consumption among adolescents. Pediatrics. 112(6 Pt 1):1321-6.

Chu, N. and Pan, W.P. (2007). Prevalence of obesity and its comorbidities among schoolchildren in Taiwan. Asian Pacific Journal of Clinical Nutrition.16 (S2):601-607.

Coon, K.A., Goldberg, J., Rogers, B.L. and Tucker, K.L., (2001). Relationships between use of television during meals and children's food consumption patterns. Pediatrics. 107:E7.

Dubois, L., Farmer, A., Girard, M. and Peterson, K. (2008). Social factors and television use during meals and snacks is associated with higher BMI among pre-school children. Public Health Nutrition. 11(12), 1267-1279.

Food and Nutrition Policy of Sri Lanka, 2004-2010 (2004). Office of the advisor to the Prime Minister on sustainable development and Chairman of the Inter Ministerial Committee on Food Security. Print \& Print Graphics (Pvt.) Ltd: Colombo 10, Sri Lanka.

Field, A.E., Gillman, M.W., Rosner, B., Rockett, H.R. and Colditz, G.A. (2003). Association between fruit and vegetable intake and change in body mass index among a large sample of children and adolescents in the United States. International Journal of Obesity. 27:821-826. 
Gillespie, S. and Haddad, L. (2001). Attacking the double burden of malnutrition in Asia and the Pacific. Asian Development Bank \& the International Food Policy Research Institute. (ISBN 971-561-366-7)

Halford, J.C., Gillespie, J., Brown, V., Pontin, E.E. and Dovey, T.M., (2004). Effect of television advertisements for foods on food consumption. Appetite. 42, 221-225.

Hossain, P., Kawar, B. and Nahas, M.E. (2007). Obesity and diabetes in the developing world - A growing challenge (perspective) New England Journal Medicine. 356(3): 213 -215

Lee, K., Lee, S., Kim, S.Y., Kim, S.J. and Kim, Y.J. (2007). Percent body fat cutoff values for classifying overweight and obesity recommended by the international obesity task force (IOTF) in Korean children. Asia Pacific Journal of Clinical Nutrition. 16 (4): 649-655.

Mian, R.M.A., Ali, M., Ferroni, P.A. and Underwood, P. (2002). The nutritional status of school-aged children in an urban squatter settlement in Pakistan. Pakistan Journal of Nutrition. 1(3):121-123.

MRI (2001). A survey report: Assessment of anaemia status in Sri Lanka. Medical Research Institute, Ministry of Health.

Munasinghe, D.L.L., Naushad, M.N.M., Kumudini, S.Y.N., Jayaweera, M.N.S. and Silva, K.D.R.R. (2008). Prevalence of overweight and obesity among children attending schools in the city of Colombo: a comparative study. Abstracts booklet of Scientific Sessions of the Nutrition Society 2008. 18.

NCHS/CDC (2000). In EpiInfo 3.5.1 [on line]. [Accessed on 20.05.2007]. Available at http://www.cdc.gov/epiinfo/downloads.htm

Olivares, S., Kain, J., Lera, L., Pizarro, f., Vio, F. and Moron, C. (2004). Nutritional status, food consumption and physical activity among children: a descriptive study. European Journal of Clinical Nutrition. 58: 1278-1285.

Sluijs, E.M.F.V., Skidmore, P.M.L., Mwanza, K., Jones,A.P., Callaghan, A.M., Ekelund, U., Harrison, F., Harvey, I., Panter, J., Wareham, N.J., Cassidy A. and Griffin, S.J. (2008). Physical activity and dietary behaviour in a population-based sample of British 10-year old children: the SPEEDY study (Sport, Physical activity and Eating behaviour: Environmental determinants in young people). BMC Public Health. 8:388.

Wardle, J., Brodersen, N.H., Cole, T.J., Jarvis, M.J. and Bonitace, D.R. (2006). Development of adiposity in adolescence: five year longitudinal study of an ethnically and socioeconomically diverse sample of young people in Britain. British Medical Journal [on line]. [Accessed on 20.05.2009]. Available at bmj.com - doi 10.1136/bmj.38807.594792.AE

WHO (1995). Physical status: the use and interpretation of anthropometry. Report of a WHO expert Committee. Technical Report Series No. 854. Geneva: World Health Organization.

Wickramasinghe, V.P., Lamabadusuriya, S.P., Atapattu, N., Sathyadas, G., Kuruparanantha, S. and Karunarathne, P. (2004). Nutritional status of school children in an urban area of Sri Lanka. Ceylon Medical Journal. 49 (4):114-8. 